\title{
Failure Analysis of a Composite Cylinder
}

\author{
S. Bhavya ${ }^{1}$, P. Ravi Kumar ${ }^{2}$, Sd. Abdul Kalam ${ }^{2}$ \\ ${ }^{l}$ M.Tech Student, ${ }^{2}$ Asst. Professor, Mech. Engg. Dept., P.V.P. Siddhartha Institute of Technology, Vijayawada, \\ A.P., India.
}

\begin{abstract}
Composite cylinders are high-strength containers made from a mixture of fibre glass or carbon fibers and a plastic resin typically epoxy. A lamina is assumed to be homogeneous and the mechanical behavior is characterized by a set of equivalent or effective moduli and strength properties. In the phenomenological approach, the lamina properties are determined experimentally by conducting tests on a single lamina or a laminate. Once the mechanical properties of the ply are known the initial failure of the ply within a laminate or structure can be predicted by applying an appropriate failure criterion. Failure types are dependent on loading, stacking sequence, and specimen geometry. There are many proposed theories to predict the one-set of failures. Most of failure criteria are based on the stress state in a lamina. The present work aims to determine the effect of diameter-to-thickness ratio ' $S$ ' with respect to failure pressure of a four layers, introduction of hoop layers at ends on four layered cylinder and introduction of hoop layers at middle of six layered angle-ply laminated cylinder which is analyzed by using Finite Element software ANSYS. The variation of failure pressure with respect to fiber angles was also presented in this work.
\end{abstract}

Key words: Composite cylinder, Failure Analysis, FEM, Fiber angle, FRP, Lamina.

\section{Introduction}

Tomonori Kaneko et al. [1] have conducted impact analysis of pressurized cylinder and studied the influence of inner pressure on failure modes and the impulse, load at penetration. They have noticed that, when there is too much inner pressure, the failure mode changes and there is a possibility of burst failure.

Velosa et al. [2] studied a new generation of composite pressure vessels for large scale market applications. The vessels consist on a thermoplastic liner wrapped with a filament winding glass fiber reinforced polymer matrix structure. Prototype pressure vessels were produced in the defined conditions to be submitted to pressure tests. They were compared between the FEM simulations and experimental results.

Teng and $\mathrm{Hu}$ [3] have done Behavior of FRP-jacketed circular steel tubes and cylindrical Shells under axial compression. From the numerical results FRP jacketing is a very promising technique for the retrofit and strengthening of circular hollow steel tubes. From finite element results for FRP-jacketed thin cylindrical shells under combined axial compression and internal pressure shows that FRP jacketing is also an effective strengthening method for such shells failing by elephant's foot collapse near the base.

Spagnoli et al. [4] has done Numerical simulation of glass-reinforced plastic cylinders under axial compression. The results of a numerical simulation study for the buckling behavior of laminated composite cylinders are presented. He concluded that Comparison of numerical and experimental results indicated good correlation in terms of stiffness and buckling modes, as well as the relative influence of laminate orientation and thickness variations on the buckling strength.

Ahmadian and Bonakdar [5] used a Static and modal analyses of laminated hollow cylinders subjected to various kinds of loadings and boundary conditions are performed using 16-node cylindrical super element. The accuracy of the results is evident from comparison of the results with exact solution method and conventional finite element. The element can predict the structural behavior of laminated cylinders in complex loading and boundary conditions in an efficient manner.

James et al. [6] have done Stress Analysis in rotating composite cylindrical shells. Stresses in composite cylindrical shells rotating with a constant speed about their longitudinal axis were analyzed. Each ply or ply group is treated as a separate thin layer of homogeneous and orthotropic material under the interracial stresses as surface loading. The radial stress is determined in terms of the circumferential stress through the equilibrium condition, and an average compatibility condition through the thickness of the thin layer is used.

Madhavi et al. [7] have done the project on Design and Analysis of Filament Wound Composite Pressure Vessel with Integrated end Domes. Material characterization of FRP of carbon T300/Epoxy for various configurations as per ASTM standards is experimentally determined using filament winding and matched die mould technique. The mechanical and physical properties thus obtained are used in the design of the composite shell. The results can be utilized to understand structural characteristics of filament wound pressure vessels with integrated end domes.

David L. Gray and Daniel J. Moser [8] have developed a method to analyze filament wound composite pressure vessel using the ABAQUS finite element analysis program. They have computed the orthotropic 
engineering constants on an element by element basis to accurately predict the structural response of a composite overwrapped pressure vessel under internal pressure.

Starbuck et al. [9] have done stress analysis of laminated composite cylinders under non-axisymmetric loading. The geometry of a composite cylinder is axisymmetric but in many cases the applied loads are nonaxisymmetric and more rigorous analytical tools are required for an accurate stress analysis. Parametric design trade studies can be easily and quickly computed using this closed-form solution. A computer program that was developed for performing the numerical calculations is described.

Gerson et al. [10] have done micro structural analysis in asymmetric and un-balanced composite cylinders damaged by internal pressure. The samples tested, in a total of five cylinders, were collapsed by internal pressure of $15 \mathrm{MPa}$. Optical and scanning electron micrography of fractured surfaces of the cylinders is presented and they show that the failures occurred by matrix failures, as debonding, transversal cracks and delamination and fiber failure, as transversal and longitudinal failures. The fracture types and modes were also determined.

Doh and Hong [11] conducted an experiment to study the burst failure of a filament wound pressure vessel composed of T-800 graphite epoxy. A degenerated finite shell element was implemented for analysis. A progressive failure analysis was performed by using failure criteria with a property degradation model.

Dr. Rani Haj Ali et al. [12] combined micromechanical and cohesive finite element modeling approach to predict the failure of a FRP composite under Mode-I and Mode-II loading conditions. A micromechanical constitutive model was used to capture the non linear material response. Calibration was achieved based on one specific geometry, while verification of crack growth was done for crack geometries. For thick section composites, a mixed mode fracture failure criterion was proposed.

Aziz Onder [13] proposed that mechanical behavior is characterized by a set of equivalent or effective module and strength properties. Lamina properties were determined by a phenomenological approach. Analytical method, Finite element method and experimental method were applied to determine First Failure pressure of composite pressure vessel. A glass epoxy composite layer is used and are oriented symmetrically or anti symmetrically. The Tsai $\mathrm{Wu}$ criterion is used to compute first failure pressure of composite layers.

Pecknold and Rahman [14] have studied Micromechanics-based structural analysis of thick laminated composites. The material model consists of two modules: (1) a micro-model of a unidirectional lamina, containing the basic 3D constitutive information for fiber and matrix constituents; and (2) a sub laminate model that enforces equilibrium of tractions between lamina, and delivers 3D homogenized stresses and strains and material tangent stiffness's. This integrated approach provides the information required for evaluating damage and failure conditions at the micro structural level.

Indhrani [15] Fiber Reinforced Polymer (FRP) confined concrete columns have been developed for new construction and rebuilding of concrete piers/piles in engineering structures. A 3-D finite element model of FRP confined concrete column was developed using ANSYS. Based on the FEA results, a test data base was developed taking into account all the possible ranges of the design parameters which affect the confined concrete strength.

Christos et al. [16] investigated structural performance of fiber reinforced composite pressure vessels, designed for pressured shelters for planetary exploration. They have utilized an integrated computer code for the simulation of damage initiation, growth, and propagation under pressure. Three different ply layers are considered to investigate the influence of fiber orientation on load carrying capability and durability. Each layer is independently investigated due to gradual pressurization of the shelter.

Scott Poveromo et al. [17] A major problem in the construction industry is building a structure that can withstand cyclic axial and cyclic lateral loads during an earthquake. One solution to protect these columns from earthquakes is to retrofit the RC columns using fiber-reinforced plastic (FRP) composites. This paper discusses the common failure modes which RC columns exhibit during an earthquake. FRP composites can potentially enhance the shear strength, flexural strength, toughness, and ductility of RC columns.

Numerical simulation of glass-reinforced plastic cylinders under axial compression was presented by authors [1] to [4]. Authors [5] to [8] proposed an Analysis of a Composite Overwrapped Pressure Vessel by using finite element analysis program. Formulation to finite element technique and developing the failure analysis of a pressurized FRP cylinder under transverse impact loading was presented by authors [9] and [10]. Experimental study and analytical modeling, failure pressure, micro mechanics based structural analysis of thick laminated composite cylinders was presented by authors [11] to [17]. It is clear that the Failure analyses of FRP composite cylinders have not been investigated. There is a scope for failure analysis of FRP composite cylinders by varying the parameter ' $\theta$ ' in angle-ply laminates.

\section{Failure Analysis}

To analyze the strength of any laminated composite, strength theories are required. Failure analysis is a tool for predicting the strength of a laminated composite, containing several plies with different orientations, under complex loading conditions using strength data obtained from uniaxial tests of unidirectional plies and 
strength theories. There are numerous failure criteria for composite materials as a direct result of the complex nature of observed failure phenomena. These criteria are only useful if they can be incorporated into a progressive damage analysis, which usually means that they must be compatible with a finite element formulation.

Different types of failure criteria have been used for determining failure of composite laminates. In general, the failure criteria are categorized into two: independent and interactive (or quadratic polynomial) criteria. An independent criterion, such as maximum stress or maximum strain, is simple to apply and more significantly, tells the mode of failure, but it neglects the effect of stress interactions. For this reason, these criteria are quite conservative. An interactive criterion, such as Tsai-Wu, Tsai-Hill, Hoffmann includes stress interactions in the failure mechanism and predicts first ply failure but it requires some efforts to determine parameters. In general, interactive theories based on curve fitting, like the Tsai-Wu theory, are better at predicting failure of a single lamina. All comparisons were made with very limited available experimental data in two dimensional form. A comprehensive evaluation of the failure theories in three dimensional form would require data under three dimensional state of stress.

\subsection{Maximum Stress Theory}

The maximum stress theory states that failure will occur when at least one stress component along one of the principle material axes reaches the magnitude of corresponding strength in that direction. The complex stress system in the lamina is transformed in to stresses along the principle material axes. Failure is defined by

Maximum Stress Failure Criteria $=$ Maximum of $\left(\sigma_{1} / \mathrm{F}_{1}, \sigma_{2} / \mathrm{F}_{2}, \sigma_{3} / \mathrm{F}_{3}, \tau_{4} / \mathrm{F}_{4}, \tau_{5} / \mathrm{F}_{5}, \tau_{6} / \mathrm{F}_{6}\right)$

Where $\mathrm{F}_{1}=\mathrm{F}_{1 \mathrm{~T}}$ when $\sigma_{1}>0$ (or) $-\mathrm{F}_{1 \mathrm{C}}$ when $\sigma_{1}<0$

$\mathrm{F}_{2}=\mathrm{F}_{2 \mathrm{~T}}$ when $\sigma_{2}>0$ (or) $-\mathrm{F}_{2 \mathrm{C}}$ when $\sigma_{2}<0$

$\mathrm{F}_{3}=\mathrm{F}_{3 \mathrm{~T}}$ when $\sigma_{3}>0$ (or) $-\mathrm{F}_{3 \mathrm{C}}$ when $\sigma_{3}<0$

$\sigma_{1}, \sigma_{2}, \sigma_{3}=$ Normal stress components along the principle material directions

$\tau_{4}, \tau_{5}, \tau_{6}=$ Shear stress components along the principle material directions directions

$\mathrm{F}_{1 \mathrm{~T}}, \mathrm{~F}_{1 \mathrm{C}}, \mathrm{F}_{2 \mathrm{~T}}, \mathrm{~F}_{2 \mathrm{C}}, \mathrm{F}_{3 \mathrm{~T}}, \mathrm{~F}_{3 \mathrm{C}}=$ Limiting tensile and compressive Strengths along the principle material

$\mathrm{F}_{4}, \mathrm{~F}_{5}, \mathrm{~F}_{6}=$ Limiting shear strength along the principle material directions

2.2 Tsai - Wu Failure Theory

Tsai-Wu failure theory is most general and it clearly distinguishes between the tensile and compressive strengths. This failure theory is based on the total strain energy failure theory of Beltrami. Tsai-Wu assumes the expression

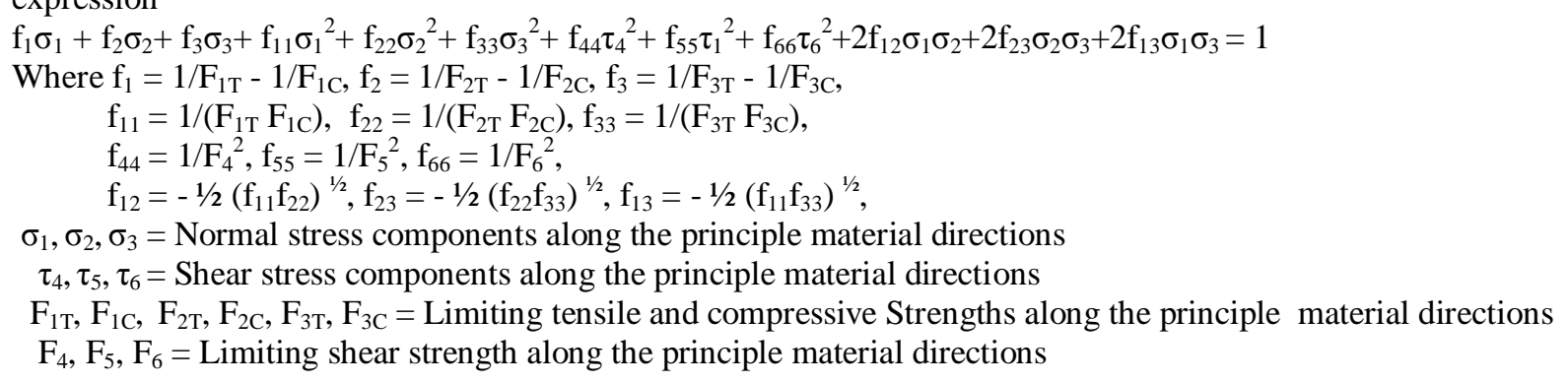

\section{PROBLEM MODELING}

The present work deals with the Failure analysis of the thick FRP composite cylinder. The main aim is to predict the Failure pressure of open ended composite cylinder, which is subjected to internal pressure load.

\subsection{Geometric Modeling}

The geometry of the problem is:

Diameter of the cylinder $=100 \mathrm{~mm}$,

Thickness of the cylinder $=$ Dia. of cylinder/S

Where ' $\mathrm{S}$ ' is the diameter to thickness ratio.

'S' values varies from 5 to 100 . 


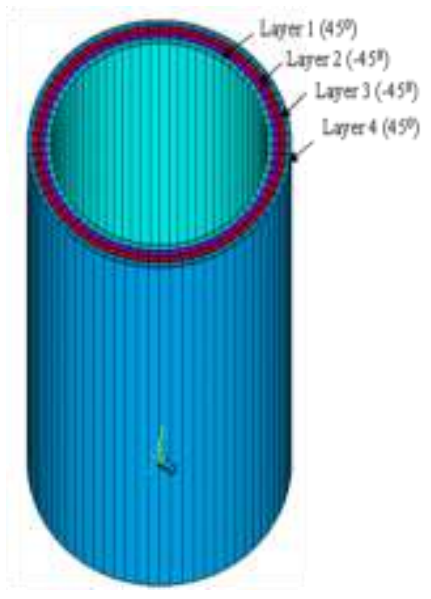

Fig. 1 Composite Cylinder with Four Layers

\subsection{Finite Element Modeling}

'The problem is modeled in ANSYS software and the finite element mesh is generated using SOLID 191 element on four volumes corresponding to four layers of laminate structure. Solid 191 is a 20node second order brick element having three degrees of freedom at each node and is suitable to incorporate orthotropic material properties. The finite element model is generated in ANSYS software for angle-ply laminate having stacking sequence of $(\theta /-\theta /-\theta / \theta)$, Where $\theta$ is fiber angle. The mesh refinement is carried out until the radial stresses at inner and outer surfaces of the cylinder closely matches with applied pressure and zero respectively.

\subsection{Boundary conditions and Loads}

At the top face of the cylinder, degrees of freedom in Z-direction (axial) are constrained. An Internal pressure of $1 \mathrm{MPa}$ is applied on the inner surface of the cylinder (Fig. 2).

\subsection{Stacking Sequence}

Stacking sequence considered for the four/six/eight layered cylinder are

- $\quad$ Four layered cylinder $(\theta /-\theta /-\theta / \theta)$

- Six layered cylinder $\quad(90 / \theta /-\theta /-\theta / \theta / 90)$.

- $\quad$ Eight layered cylinder $(90 / \theta /-\theta / 90 / 90 /-\theta / \theta / 90)$.

Where ' $\theta$ ' is fiber angle varied from $0^{\circ}$ to $90^{\circ}$ with an increment of $15^{\circ}$.

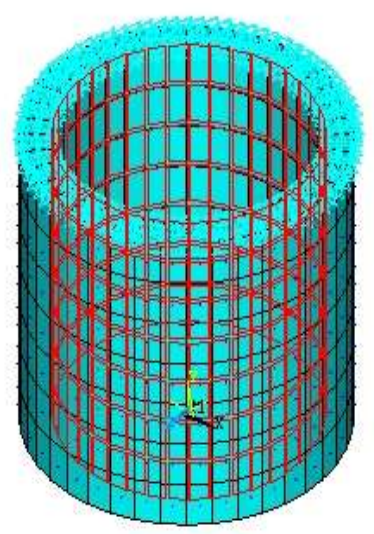

Fig.2 FE model with boundary conditions

\subsection{Material properties}

The following material properties are used. Orthotropic material (Carbon Epoxy)
$\mathrm{E}_{1}=147 \mathrm{Gpa}$,
$v_{12}=0.27$,
$\mathrm{E}_{2}=10.3 \mathrm{Gpa}$,
$v_{23}=0.54$,
$\mathrm{E}_{3}=10.3 \mathrm{GPa}$
$v_{13}=0.27$
$\mathrm{G}_{23}=3.7 \mathrm{Gpa}$,
$\mathrm{G}_{12}=7 \mathrm{Gpa}$,
$\mathrm{G}_{13}=7 \mathrm{GPa}$ 
Failure Analysis Of A Composite Cylinder

\section{Validity Of The Present Analysis}

The present finite element model is validated by computing radial stress and circumferential stresses at the inner and outer surfaces of an isotropic cylinder.

\begin{tabular}{|c|l|c|c|c|}
\hline Layer No & \multicolumn{1}{|c|}{ Stress } & $\begin{array}{c}\text { Theoritical } \\
(\mathbf{M p a})\end{array}$ & $\begin{array}{c}\text { Ansys } \\
\text { (Mpa) }\end{array}$ & \% Error \\
\hline \multirow{2}{*}{$\mathbf{1}$} & Radial Stress & -1.000 & -1.015 & 1.500 \\
\cline { 2 - 5 } & Circumferential Stress & 5.050 & 5.219 & 3.343 \\
\hline \multirow{2}{*}{} & Radial Stress & -0.690 & -0.684 & 0.839 \\
\cline { 2 - 5 } & Circumferential Stress & 4.740 & 4.743 & 0.058 \\
\hline \multirow{2}{*}{} & Radial Stress & -0.425 & -0.421 & 1.006 \\
\cline { 2 - 5 } & Circumferential Stress & 4.475 & 4.478 & 0.055 \\
\hline \multirow{2}{*}{$\mathbf{n}$} & Radial Stress & -0.197 & -0.194 & 1.727 \\
\cline { 2 - 5 } & Circumferential Stress & 4.247 & 4.251 & 0.074 \\
\hline
\end{tabular}

\section{Discussion On Results}

The finite element model is generated in ANSYS software. The results are taken for various cases

- Comparison of failure pressures for Symmetric sequence $(\theta /-\theta /-\theta / \theta)$ with Anti Symmetric sequence $(\theta /$ $-\theta / \theta /-\theta)$ with respect to fiber angle for a four layered composite cylinder.

- Effect of Hoop layers on failure pressure of composite cylinders.

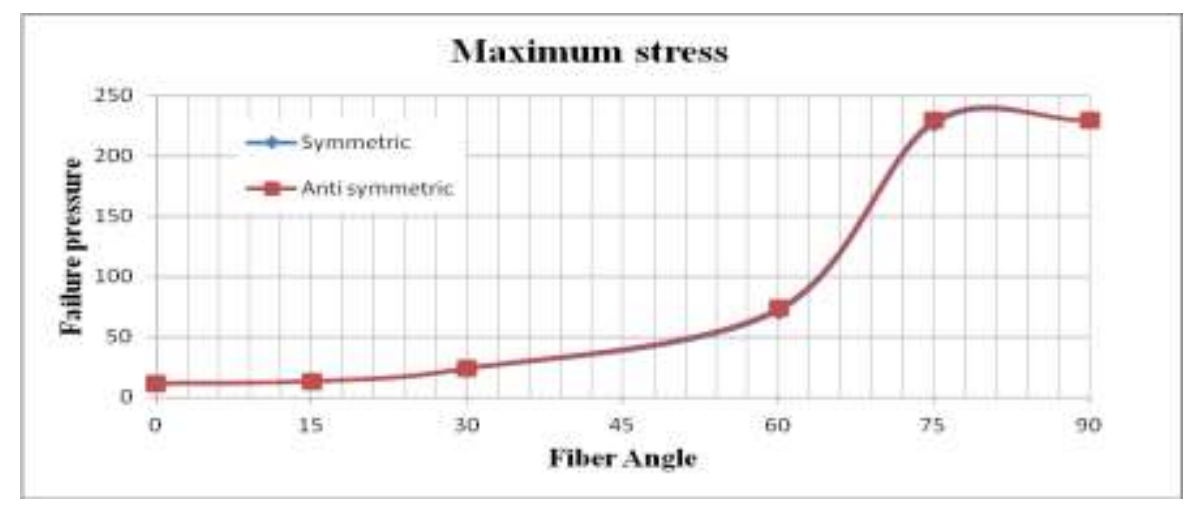

Fig. 3 Variation of Failure Pressure with respect to Fiber Angle according to Maximum Stress criteria Variation of Failure Pressure with respect to fiber angles according to Maximum Stress criteria for both Symmetric and Anti Symmetric Stacking Sequence is shown in fig.3. It is observed that there is no variation in terms of failure pressure for all angles for both symmetric and anti symmetric stacking sequence. Failure pressure increases rapidly from fiber angle 60 onwards in both symmetric and Anti symmetric Stacking sequence.

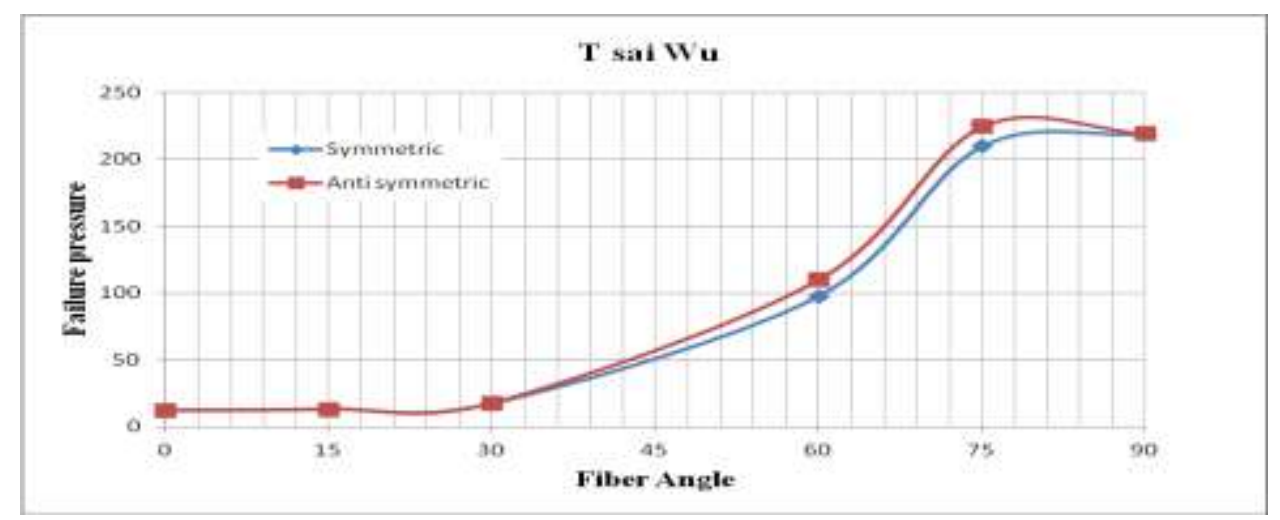

Fig .4 Variation of Failure Pressure with respect to Fiber angles according to Tsai Wu criteria

Variation of Failure Pressure with respect to fiber Angles according to Tsai Wu criteria for both Symmetric and Anti Symmetric Stacking Sequence is shown in fig.4. It is observed that there is Slight variation of failure pressure takes place between fiber angles 45 to 75 . Failure pressure increases gradually with respect to fiber angle in both symmetric and Anti symmetric Stacking sequence. 


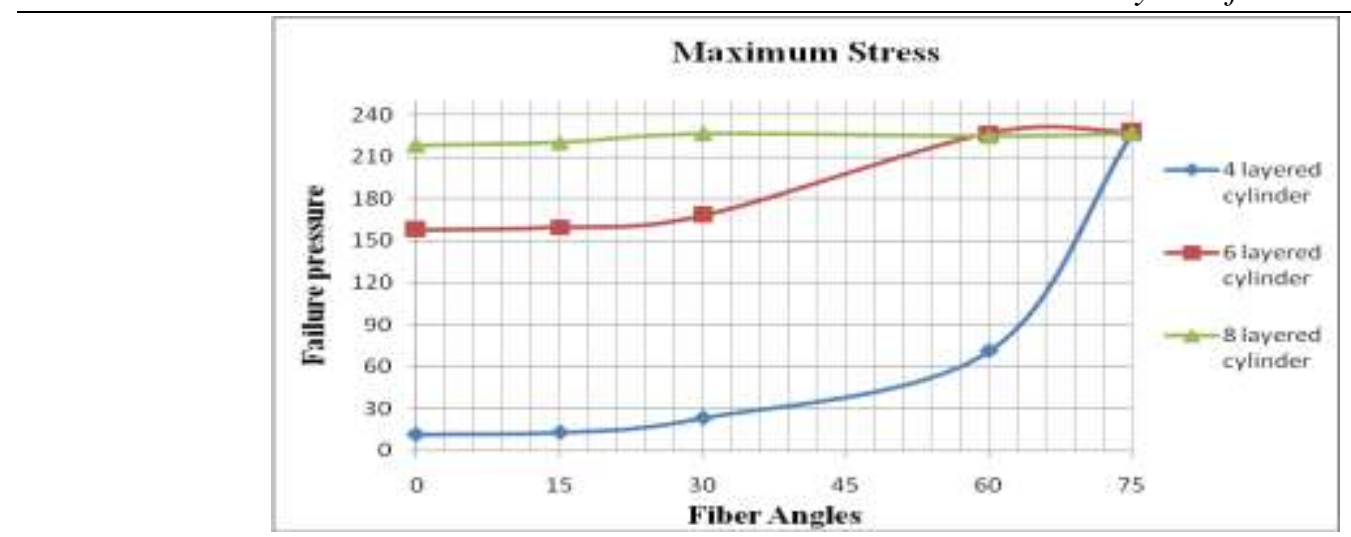

Fig. 5 Variation of Failure Pressure with respect to Fiber angles according to Maximum stress criteria for 4, 6 and 8 layered cylinder

Variation of Failure Pressure with respect to fiber angles according to Maximum stress criteria for 4, 6 and 8 layered cylinder is shown in figure 5. For all the angles, 8 layered cylinders have higher failure pressure values than 4 and 6 layered cylinders. At angle 0 , failure pressure for 4 layered cylinders is $11.26 \mathrm{M} \mathrm{Pa}$, whereas for 8 layered cylinders by introducing hoop layers, the pressure at which failure occurs is $219.68 \mathrm{M} \mathrm{Pa}$. so due to hoop layer for the same thickness eight layered cylinder offers high strength than four and six layered cylinder.

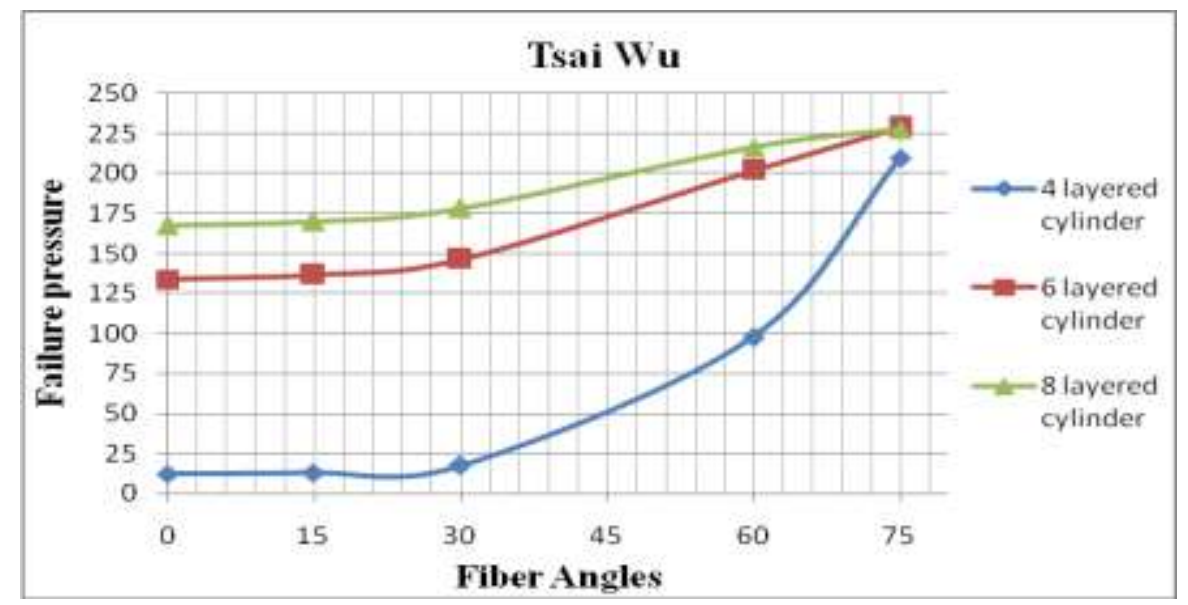

Fig 6 Variation of Failure Pressure with respect to Fiber angles according to Inverse Tsai Wu criteria for 4 and 6 layered cylinder

Variation of Failure Pressure with respect to Angles according to Tsai Wu criteria for 4, 6 and 8 layers is shown in figure 6. For all the angles 8 layers have higher failure pressure values than 4 and 6 layers. At fiber angle 0 , failure pressure for 4 layers is $12.07 \mathrm{M} \mathrm{Pa}$, whereas for 8 layers by introducing hoop layers, the pressure at which failure occurs is $168.20 \mathrm{M}$ Pa. so due to hoop layer for the same thickness eight layered cylinder offers high strength than four and six layered cylinder.

\section{Conclusions}

Analysis of FRP composite cylinder has been studied in the present work. The laminates considered for the present analysis are four-layered angle-ply and six layered laminate covered by hoop layers on top and bottom of four angle-ply layers and also an eight layered laminate. The effect of Failure pressure with respect to angles for different types of criteria like Maximum stress, Tsai Wu is presented.

By comparing Symmetric and Anti Symmetric stacking sequence for a four layer laminated cylinder, for both criteria's Failure pressure is almost equal for all fiber angles. From this it is concluded that there is no effect of symmetry in stacking sequence. For all the fiber angles eight layers laminate $(90 / \theta /-\theta / 90 / 90 /-\theta / \theta$ 190) have higher failure pressure values than 4 and 6 layered cylinder. At angle 0 , failure pressure for 4 layered cylinders is $11.26 \mathrm{M} \mathrm{Pa}$, whereas for 6 layered cylinders by introducing hoop layers, the pressure at which failure occurs is $157.65 \mathrm{M} \mathrm{Pa}$. For 8 layered cylinders by introducing hoop layers, the pressure at which failure occurs is $219.68 \mathrm{M} \mathrm{Pa}$. From this it is concluded that due to introduction of hoop layers strength of cylinder can be increased. 


\section{References}

[1] Tomonori Kaneko, Sadayuki Ujihashi, Hidetoshi Yomoda and Shusuke Inagi, "Finite element method failure analysis of a pressurized FRP cylinder under transverse impact loading", Thin-Walled Structures 46, 2008, pp. 898-904.

[2] J. C. Velosa, J. P. Nunes, P. J. Antunes, J. F. Silva and A. T. Marques, "Development of a new generation of filament wound composite pressure cylinders", Ciencia e Tecnologia dos Materiais, Vol.19, 2007.

[3] J.G. Teng andY.M. Hu, "Behaviour of FRP-jacketed circular steel tubes and cylindrical Shells under axial compression", Construction and Building Materials 21, 2007, pp. 827-838.

[4] Spagnoli, A. Y. Elghazouli and M. K. Chryssanthopoulos, " Numerical simulation of glass-reinforced plastic cylinders under axial compression”, Marine Structures 14 (2001), pp. 353-374.

[5] M. T. Ahmadian and M. Bonakdar, "A new cylindrical element formulation and its application to structural analysis of laminated hollow cylinders",Finite Elements in Analysis and Design 44, 2008, pp.617 - 630.

[6] James Ting-Shun Wang \& Chien-Chang Lin, "Stresses in rotating composite cylindrical shells", Composite Structures 25, 1993, pp. 157-164.

[7] M. Madhavi, K. V. J. Rao and K. Narayana Rao, "Design and Analysis of Filament Wound Composite Pressure Vessel with Integrated-end Domes”, Defence Science Journal, Vol. 59, No. 1, 2009, pp. 73-81.

[8] David L. Gray, Daniel J. Moser, "Finite Element Analysis of a Composit overwrapped pressure vessel", 40 AIAA/ASME/SAE/ASEE Joint Propulsion Conference and Exhibit Florida, 2004.

[9] J. Michael Starbuck, "stress analysis of laminated composite cylinders Under non-axisymmetric loading", Lockheed Martin Energy Research Corporation, DE-AC05-96OR22464.

[10] Gerson Marinucci, Arnaldo H.P. de Andrade, "Micro structural analysis in asymmetric and un-balanced composite cylinders damaged by internal pressure", Composite Structures, 2004.

[11] Y.D Doh and C.S.Hong "Progressive Failure Analysis for filament wound pressure vessel", Department of Aerospace Engineering, Korea Advanced institute of Science and Technology. 373-1 Kusong-dong, yusung-gu, Taejon, 305-701, Korea.

[12] Rani Fayez El-Hajjar "Experimental Study And Analytical Modeling Of Translayer Fracture In Pultruded FRP Composites" Doctor of Philosophy in the School of Civil and Environmental Engineering, Georgia Institute of Technology, May 2004.

[13] Aziz Önder "First Failure Pressure Of Composite Pressure Vessels" Graduate School of Natural and Applied Sciences of Dokuz Eylül University, February, 2007.

[14] D. A. Pecknold and S. Rahman, "Micromechanics-based structural analysis of thick laminated composites", Computers \& Structures, vol. 51. No. 2, (1994) pp. 163-179.

[15] Indrani Venkata Volety "Modeling Of Fiber Reinforced Polymer Confined Concrete Cylinders" Louisiana State University, May, 2006.

[16] Christos C. Chamis, pascal k. Gotsis and Levon Minnetyan, "Progressive Fracture and Damage Tolerance of Composite Pressure Vessels".

[17] Scott Poveromo, "The Use of Fiber Reinforced Polymer Composites to Retrofit Reinforced Concrete Bridge Columns" MATE 115, Fall 2003.

[18] ANSYS Reference Manuals, 2007. 